Fanum

Sociológico

\section{Forum Sociológico}

Série II

28 | 2016

Interculturalidade e educação

\title{
Um olhar sobre as experiências de mulheres imigrantes em cursos EFA - Histórias de vida
}

A look over migrant women' experiences in EFA courses - Life stories

Luís Filipe da Câmara da Fonseca

\section{(2) OpenEdition}

Journals

Edição electrónica

URL: https://journals.openedition.org/sociologico/1426

DOI: $10.4000 /$ sociologico. 1426

ISSN: 2182-7427

Editora

CICS.NOVA - Centro Interdisciplinar de Ciências Sociais da Universidade Nova de Lisboa

Refêrencia eletrónica

Luís Filipe da Câmara da Fonseca, «Um olhar sobre as experiências de mulheres imigrantes em cursos EFA - Histórias de vida», Forum Sociológico [Online], 28| 2016, posto online no dia 31 dezembro 2016, consultado o 29 março 2022. URL: http://journals.openedition.org/sociologico/1426 ; DOI: https://doi.org/10.4000/sociologico.1426 


\title{
UM OLHAR SOBRE AS EXPERIÊNCIAS DE MULHERES IMIGRANTES \\ EM CURSOS EFA - HISTÓRIAS DE VIDA
A LOOK OVER MIGRANT WOMEN' EXPERIENCES IN EFA COURSES - LIFE STORIES

\author{
Luís Filipe da Câmara da Fonseca \\ Centro de Emprego e Formação Profissional de Setúbal
}

\begin{abstract}
Resumo
Este artigo é fruto da dissertação de mestrado em Ciências da Educação, intitulada "Um Olhar Sobre as Experiências de Mulheres Imigrantes em Cursos EFA - Histórias de Vida", submetida à Faculdade de Ciências Sociais e Humanas da Universidade Nova de Lisboa.

O autor teve como objectivo principal saber por que razão as mulheres imigrantes, que interromperam os seus estudos nos países de origem, decidiram voltar a estudar, nomeadamente em cursos de Educação e Formação de Adultos (EFA) em Portugal.

Os relatos das participantes permitiram conhecer os seus percursos escolares nos países de origem, os motivos que as levaram a inscrever-se nos referidos cursos, as dificuldades enfrentadas, assim como também perceber como encaram a educação e a formação, e que expectativas têm após finalizarem os seus cursos.
\end{abstract}

Palavras-chave: mulheres imigrantes, educação e formação de adultos, cursos EFA de nível secundário, aprendizagem ao longo da vida

\begin{abstract}
This study subsumes the dissertation entitled "A look over migrant women' experiences in EFA courses - Life stories", submitted to the Universidade Nova de Lisboa as fulfillment of requirements to obtain the degree of Master in the Science of Education.

This research aims to investigate the reasons why immigrant women, after a break in studies in their countries, decided to go back to school and enroll in EFA courses in Portugal.

The narratives of the subjects allowed to follow their school careers in their home countries, the reasons that led them to enroll in courses EFA in Portugal, as well as the difficulties they pass through, and then to realize what does education and training represent to these subjects and what expectations do they have after completing their courses.
\end{abstract}

Keywords: immigrant women, adult education, EFA courses secondary level, lifelong education

\section{Introdução}

As nossas funções formativas no Centro de Emprego e Formação Profissional de Setúbal despertaram-nos o interesse pelo tema deste estudo. O desejo de aumentar os nossos conhecimentos e melhorar as nossas práticas profissionais, assim como de deixar o nosso contributo para a formação e divulgação de conhecimento científico, levou-nos a assumir o papel de "professor-investigador"1.
Com este estudo procurámos contribuir para uma melhor compreensão acerca das mulheres imigrantes que se encontram em formação em cursos EFA, conhecendo as suas histórias de vida.

A leitura da tese de doutoramento de Dulce Silva (2013), intitulada "Voltar à escola 20 anos depois: um desafio pessoal e social", influenciou a formulação das nossas questões de partida e objectivos de estudo.

Os objectivos que nortearam o desenvolvimento desta investigação foram identificar as razões 
pelas quais as mulheres imigrantes abandonaram os estudos no seu país de origem, descrever as principais motivações declaradas pelas formandas que procuraram novamente o ensino num país que não é o seu (estudo em Cursos EFA), interpretar essas motivações e reflectir sobre a implicação do conhecimento das motivações e das expectativas dos adultos na promoção do ensino em Cursos EFA.

Tal como outros investigadores, como por exemplo Mendes (2008) e Miranda (2009), decidimos que a população alvo do nosso estudo deveria pertencer às nacionalidades imigrantes mais representativas no nosso país, brasileira e cabo-verdiana, mas também contemplar mulheres de países do leste europeu.

Este artigo encontra-se organizado em quatro secções. A primeira corresponde à introdução. A segunda secção refere-se ao enquadramento teórico, no qual dedicamos atenção aos conceitos de imigrante e de estrangeiro e à literatura sobre as mulheres imigrantes em Portugal, a aprendizagem ao longo da vida e os cursos EFA. Na terceira seção apresentamos a descrição do estudo realizado, o objecto de estudo, especificando-se a estratégia de pesquisa e os instrumentos utilizados. Por fim, na última secção, apresentamos a conclusão.

\section{Enquadramento teórico}

No sentido de conhecermos melhor a população alvo do nosso estudo, a mulher imigrante, tivemos em atenção os conceitos de imigrante e de estrangeiro e a literatura sobre mulheres imigrantes em Portugal, a aprendizagem ao longo da vida (ALV) e os cursos EFA.

O conceito de imigrante confunde-se com o conceito de estrangeiro, sendo muitas vezes utilizado como sinónimo, tanto nos meios de comunicação social, como na literatura especializada e relatórios das entidades que concebem dados estatísticos relativos a estrangeiros (Cabete, 2010; Mortágua, 2010; Rosa, Seabra e Santos, 2003). A definição de imigrante apresentada por Ferreira, Rato e Mortágua (2004) é elucidativa deste facto: "O imigrante é, por definição, um estrangeiro. É uma pessoa que não tem a nacionalidade do país que o acolheu na qualidade de imigrante, ou seja, que não prove ter nacionalidade portuguesa. Contudo, nem todo o estrangeiro é imigrante" (Ferreira, Rato e Mortágua, 2004: 26).

A definição apresentada pela União Europeia (U.E.) considera imigrantes os cidadãos de países terceiros. Atendendo a este facto, os cidadãos de Estados-Membros que se encontram instalados em Portugal não podem ser considerados imigrantes.

Pelo exposto, sentimos necessidade de explicitar que ao longo do artigo, quando utilizamos a expressão "mulheres imigrantes", estamos a referir-nos a mulheres nascidas em países que não pertencem à
U.E. e que vivem em Portugal, não incluindo uma segunda geração de mulheres nascidas neste país, nem filhas de pais imigrantes.

Os estudos sobre mulheres imigrantes no nosso país têm sido dispersos e pontuais (Miranda, 2009). Estes estudos têm sido dedicados a temas como: identidades femininas em contextos migratórios, padrões migratórios e mercado laboral. De entre estes estudos ocorre-nos mencionar o de Mendes (2008), que procurou contribuir para um melhor entendimento do processo de (re)construção identitária de mulheres imigrantes em Portugal, tendo por base as trajectórias de seis mulheres e o de Trovão e Ramalho (2010) intitulado "Repertórios femininos em construção num contexto migratório pós-colonial: Dinâmicas familiares, de género e geração".

Wall, Nunes e Matias (2008) realizaram um estudo sobre os três principais grupos de mulheres imigrantes em Portugal: cidadãs brasileiras, cabo-verdianas e ucranianas, tendo identificado dois tipos de padrões migratórios: mulheres integradas num projecto familiar e mulheres que migram sozinhas. Para além disso, identificaram uma variedade de trajectórias distintas no interior de cada perfil.

Em 2005, o SOS Racismo publicou a obra "Imigração e etnicidade - vivências e trajectórias de mulheres em Portugal", na qual faz "um recorte nas realidades das vivências no feminino e analisa a situação da mulher na condição do seu deslocamento no território da imigração (...) e reflecte sobre os encontros e desencontros étnicos" (SOS Racismo, 2005: 7).

Malheiros, Padilla e Rodrigues (2010) realizaram um estudo sobre mulheres imigrantes empreendedoras.

Porém, no que concerne a estudos que se debruçam sobre as mulheres imigrantes e a educação são poucos no nosso país. Tal como afirma Neves (2012), os estudos que envolvem a imigração e a educação têm privilegiado os filhos dos imigrantes e não os pais. Neves (2012) realizou um estudo, intitulado "A mulher imigrante brasileira no contexto educacional português: limites e possibilidades", com o objectivo de conhecer e analisar qual a importância que as mulheres imigrantes brasileiras residentes em Portugal atribuem à educação e acerca da sua inserção no contexto educacional.

Um outro exemplo é o de Estrela (2013) que realizou uma dissertação de mestrado intitulada "O leste em Portugal: a integração de imigrantes ucranianos e a educação de adultos", procurando perceber como é que estes imigrantes se têm integrado na nossa sociedade, através da inserção em percursos educativos para adultos promovidos pelo Estado.

A sociedade actual, apelidada do conhecimento, caracteriza-se pela necessidade de uma actualização permanente de conhecimentos, de aquisição de 
competências e capacidades (Ferreira, 2010). Quer as organizações quer os indivíduos vêem-se confrontados com um modelo de "sujeito aprendente", numa sociedade em que a aprendizagem ao longo da vida (ALV) se tornou uma condição imperativa para a inclusão.

A ALV assume-se como um "factor determinante" para enfrentar os desafios que as sociedades contemporâneas colocam aos cidadãos (Alves, 2010; Ávila, 2008).

Os Cursos EFA, destinados a cidadãos com idade igual ou superior a 18 anos, que pretendam concluir o ensino básico ou secundário, encontram-se organizados numa perspectiva de ALV, enquanto instrumentos promotores da (re)inserção sócio-profissional e de uma progressão na qualificação. Deste modo, ajudam a combater a pobreza, a exclusão social e a marginalização dos excluídos pelas baixas qualificações ou pelo desemprego.

Os cursos EFA podem contribuir para uma melhor integração de imigrantes na sociedade portuguesa, permitindo-Ihes adquirir as competências e as qualificações necessárias para enfrentar as exigências crescentes do mercado de trabalho. Monteiro (2011) foi um dos autores que se debruçou sobre a questão de como pode a educação de adultos contribuir para a inclusão social de grupos mais desfavorecidos. Este autor usou o exemplo de cursos EFA dirigidos a mulheres desempregadas e residentes em meio rural, procurando analisar o modo como a educação se pode transformar num passo importante para que estes adultos vejam reforçada a sua condição de cidadania e a capacidade para participarem na determinação do seu destino.

Alguns autores têm-se dedicado ao estudo dos motivos que levam os adultos a frequentar cursos EFA. Ferreira (2010) considera que os adultos se inscrevem nestes cursos devido a motivos extrínsecos, havendo diferenças significativas na natureza dos motivos, em função do género e do nível de formação frequentado. A autora refere, também, que estes adultos pretendem uma melhor gestão da sua carreira profissional e a aquisição de competências que Ihes permitam manter o emprego ou procurar outro melhor. Fonseca (2010) desenvolveu um estudo semelhante ao de Ferreira (2010). A autora procurou conhecer os motivos e as expectativas que conduzem os indivíduos à escolha e à frequência de cursos de EFA. Fonseca (2010) conclui, tal como Ferreira (2010), que os motivos mais seleccionados pelos adultos foram factores extrínsecos. Fonseca (2010) refere os motivos vocacional (enriquecimento do curriculum vitae), operacional profissional (melhoria do desempenho no trabalho) e económico (progressão profissional).

\section{Descrição do estudo realizado}

Este estudo seguiu uma metodologia qualitativa, utilizando como instrumentos de recolha de dados a entrevista em profundidade, semi-estruturada e a narrativa escrita.

Nas entrevistas foi utilizado um guião constituído por 8 blocos de questões (legitimação da entrevista; caracterização das formandas; percurso migratório; passado escolar; motivação; relação com colegas e formadores; expectativas; informação complementar).

O estudo passou por dois momentos. Num primeiro momento solicitámos uma narrativa escrita num formulário próprio intitulado "Por favor conte a sua experiência de vida até chegar a este curso EFA" e, num segundo momento, as entrevistas.

A entrevista foi dividida em duas partes: uma com perguntas fechadas envolvendo aspectos de natureza biográfica como idade, estado civil, tempo de residência em Portugal e uma segunda parte, constituída por perguntas abertas, com perguntas acerca de marcos importantes da vida das entrevistadas, do seu relacionamento com a família ao longo do tempo, a forma como vieram para Portugal, quais as motivações que conduziram à frequência de cursos EFA, assim como as suas expectativas e planos futuros.

As entrevistas foram gravadas e, posteriormente, transcritas, sendo os conteúdos analisados no conjunto de cada nacionalidade e no conjunto global das nove entrevistas. No tratamento dos dados recolhidos, recorremos à análise de conteúdo.

No que diz respeito às participantes, o estudo contou com a participação de nove voluntárias, três brasileiras, três cabo-verdianas e três mulheres de países do leste europeu que se encontravam a frequentar cursos EFA de nível secundário, num Centro de Emprego e Formação Profissional.

Participantes brasileiras. As participantes brasileiras tinham idades compreendidas entre os 31 e os 47 anos. Eram naturais do Estado de Minas Gerais, uma da cidade de Belo Horizonte e duas de Ipatinga. De acordo com vários autores como, por exemplo Miranda (2009) e Malheiros (2007), uma grande percentagem de brasileiros que se encontram em Portugal são provenientes de Minas Gerais.

Estas mulheres abandonaram cedo os estudos, duas devido às dificuldades económicas da família e outra devido ao namoro.

A decisão de deixarem o Brasil foi influenciada por amigos ou familiares a trabalhar no nosso país, tendo lá deixado filhos e vindo a casar em Portugal.

Em Portugal, tiveram dificuldades em encontrar emprego, tendo sido o desemprego e o desejo de melhorar as habilitações académicas que as levaram a inscrever-se nos cursos de técnico auxiliar de 
saúde, de técnicas de esteticismo e cosmetologia e de técnico de turismo ambiental e rural.

No que diz respeito ao relacionamento com os colegas da turma, alguns autores como Malheiros (2007) consideram que o facto de falarem português contribui para uma melhor interacção social. "Os Brasileiros são considerados em diversos estudos de opinião efectuados junto da população portuguesa como o grupo imigrante mais próximo desta" (Malheiros, 2007: 23).

Apesar das entrevistadas considerarem que a sua relação com os colegas era boa, afirmaram que não tinham amigos nas suas turmas.

Uma das entrevistadas diz já ter sido discriminada por uma colega brasileira: "Já senti preconceito na minha turma com colega brasileira de se achar superior. Mas eu não dou importância. Na vida a gente leva tantas pancadas. Chega uma altura que não é a gente estar habituados mas já temos defesas" (Vanessa, entrevista).

No que concerne à relação com os formadores, consideram que alguns são mais atenciosos do que outros e gostam de interagir com os formandos. Alguns formadores são mais expositivos e não gostam de ser interrompidos. Das três entrevistadas apenas uma disse: "Já sofri alguma discriminação por parte de alguns formadores" (Andreia, entrevista).

Participantes cabo-verdianas. As participantes cabo-verdianas tinham idades compreendidas entre os 22 e os 59 anos. Uma das entrevistadas nasceu na Ilha de Santo Antão e as restantes na Ilha de Santiago, sendo uma casada, uma em união de facto e outra divorciada. O número de filhos variava entre os dois e os quatro.

O abandono dos estudos prendeu-se com dificuldades económicas das famílias.

As três mulheres vieram para Portugal em 1971, 1987 e 2009, respectivamente. De acordo com Batalha (2008), a migração cabo-verdiana para Portugal iniciou-se nos anos 1960.

Duas das entrevistadas já exerceram várias profissões no nosso país enquanto que a mais nova tem tido muita dificuldade em encontrar emprego.

Estas mulheres inscreveram-se nos cursos EFA devido ao desemprego, por quererem melhorar as habilitações académicas e, no caso de uma delas, para ocupar o tempo. Uma das entrevistadas frequenta o curso de técnicas de auxiliares de saúde e as restantes o de cozinha e pastelaria.

Duas entrevistadas disseram que tinham um bom relacionamento com os colegas de turma e com os formadores, queixando-se apenas de haver poucas aulas práticas no curso de cozinha e pastelaria.

Apenas a entrevistada mais jovem diz: "Eu gosto desta turma mas não quero apegar-me às pessoas porque depois levo patadas. Amigos lá fora, aqui não" (Sidneia, entrevista).
Estas mulheres consideravam que seria mais fácil encontrar trabalho após a conclusão dos cursos. Duas delas pensavam que se o estágio corresse bem poderiam ficar a trabalhar no local onde este decorresse.

Participantes de países do leste europeu. As participantes de países do leste europeu tinham idades compreendidas entre os 31 e os 35 anos, sendo duas naturais da Ucrânia e outra da Moldávia. Uma das entrevistadas concluiu o 9.0 ano de escolaridade na Ucrânia, as restantes concluíram o $12 .{ }^{\circ}$, tendo uma destas frequentado o primeiro ano do curso universitário de contabilidade e finanças. São casadas e têm filhos nascidos em Portugal.

O facto de muitos ucranianos terem vindo para Portugal e de terem tido sucesso influenciou-as a decidirem emigrar, tendo uma delas vindo com o marido e as outras alguns anos depois dos respectivos maridos.

Uma das entrevistadas frequenta o curso de técnica de maquinação e programação e as outras o de aeronáutica. Os motivos que as levaram a inscrever-se nestes cursos foram o facto de se encontrarem desempregadas, de quererem melhorar as suas habilitações académicas e de quererem apostar num curso com saída profissional.

As três consideraram que tinham um bom relacionamento com os formadores, mas o mesmo não acontecia com os colegas, devido às muitas intervenções que faziam nas aulas. Se não percebem o que é dito, pedem que os formadores expliquem de novo e colocam dúvidas e questões. Os colegas não entendem e pensam que fazem isso para se evidenciarem. Duas delas consideram que os portugueses são muito desleixados com a forma como se vestem e que as pessoas que de algum modo sobressaem pela forma de vestir ou de falar são apontadas. Por isso, afastam-se da maioria dos colegas porque se sentem criticadas e discriminadas.

As entrevistadas consideraram que após a conclusão dos cursos seria fácil integrar o mercado de trabalho porque são áreas em que há oferta de emprego.

Todas as participantes deste estudo imigraram para Portugal em idade activa. Tal como afirmam Rodrigues, Correia, Pinto, Pinto e Cruz (2013), os imigrantes apresentam uma característica semelhante: grande parte deles imigra para Portugal em idade activa e desenvolve a sua actividade profissional e por vezes a vida familiar.

Contrariamente às mulheres cabo-verdianas e de países do leste europeu, no que diz respeito à decisão de emigrar as mulheres brasileiras tomaram a decisão sozinhas. Todas tinham amigas ou familiares em Portugal que as ajudaram à chegada e a encontrar local para residirem. 
Em todos os casos a motivação de emigrar foi económica. Estas mulheres revelaram, quer na narrativa de vida quer nas entrevistas, que as suas famílias tiveram problemas financeiros. No estudo de Miranda (2009), a motivação da emigração das mulheres foi a mesma. As mulheres emigraram para ganhar mais e para conquistar melhores condições de vida.

A nível profissional as profissões que ocuparam em Portugal foram muito semelhantes, ou seja, relacionadas com restaurantes, cafés e limpezas. À excepção de uma brasileira que trabalhou também em bares e de uma cabo-verdiana que desde que se encontra no nosso país apenas teve um emprego de três meses numa loja chinesa. De acordo com Costa (2009) os imigrantes em Portugal ocupam o grupo das profissões mais desfavorecidas económica e socialmente.

Rodrigues, Correia, Pinto, Pinto e Cruz (2013) explicam que, apesar das mulheres imigrantes da europa de leste deterem bons níveis de instrução, trabalham em actividades com baixos salários e desvalorizadas socialmente, como os serviços de limpeza e trabalhos domésticos.

Contudo, é de frisar que algumas das mulheres entrevistadas tiveram o seu próprio negócio por conta própria. É o caso de uma cabo-verdiana que teve uma loja de corte de cabelo e um café, de uma ucraniana que teve um café e de uma brasileira que teve três lojas de venda de produtos naturais e atendimento de nutricionista.

Dos três grupos de mulheres apenas o grupo das mulheres dos países do leste da Europa dizem não gostar muito do curso devido ao facto de não entenderem tudo o que é dito em português. As três manifestaram que os cursos são muito exigentes, principalmente para os estrangeiros que não sabem falar português. As três consideram que embora tenham muitas dificuldades em compreender tudo o que é leccionado esforçam-se muito por ter boas notas.

As entrevistadas consideram que a sua relação com os professores é boa. Costa (2011) refere que é importante existir um bom relacionamento entre formador e formando num clima de confiança, amizade e entreajuda que seja propício à aquisição de aprendizagens. Esta autora explica que por vezes há aspectos que condicionam a actuação dos formadores com os grupos de formação, como por exemplo, a heterogeneidade de idades numa mesma turma. Numa turma podem coexistir formandos de 18 com outros de cinquenta anos ou mais. Por isso, se verifica uma heterogeneidade nos conhecimentos adquiridos e até na forma de aquisição dos conteúdos.

Das entrevistadas apenas uma, brasileira, afirma ter sofrido discriminação com formadores: "Já sofri alguma discriminação por parte de alguns formadores. Principalmente nesta área em que nós estamos tirando o curso. Pela visão que muita gente tem da parte estética que vem do Brasil. Parecia que tinha medo de ser confrontada com alguma coisa. Você fica lá que você aqui está para aprender" (Andreia, entrevista).

No que diz respeito ao relacionamento com colegas estas mulheres afirmam que não têm amigos verdadeiros nas turmas que frequentam: "Eu só tenho uma amiga na turma que é ucraniana. Falo com os colegas portugueses mas não muito. Sinto alguma vergonha por não falar bem. Mas os portugueses olham muito para nós por sermos estrangeiras" (Alina, entrevista).

\section{Conclusão}

Este estudo permitiu-nos conhecer um pouco acerca dos imigrantes em Portugal através do estudo de histórias de vida de um grupo de mulheres imigrantes que se encontravam a estudar em cursos EFA.

Foi nossa intenção conhecer os motivos que conduziram ao abandono escolar das mulheres imigrantes nos seus países de origem, quais os motivos que as levaram a estudar novamente, mas desta vez no país de acolhimento, que dificuldades sentem nos cursos, como é o relacionamento com os formadores e com os colegas e que expectativas possuem para o futuro quando terminarem os cursos.

Comparando os três grupos de mulheres, brasileiras, cabo-verdianas e de países do leste europeu, percebemos que há diferenças no que diz respeito à decisão de emigrar. As mulheres brasileiras, solteiras ou divorciadas, decidem e vêm para Portugal sozinhas, enquanto que as outras o fazem tendo por base um plano efectuado com os maridos.

Embora pertencentes a comunidades diferentes as histórias de vida destas mulheres têm elementos muito semelhantes. Nos países de acolhimento tendem, independentemente das habilitações académicas a ocupar as profissões pior remuneradas e precárias. Para além disso, o desemprego e o facto de desejarem ter melhores empregos foram as razões principais que as levaram a voltar a estudar.

Foi também o desejo de melhorarem as suas vidas financeiramente que levou algumas das mulheres entrevistadas a criarem o seu próprio negócio. É o caso de uma cabo-verdiana que teve uma loja de corte de cabelo e um café, de uma ucraniana que teve um café e de uma brasileira que teve três lojas de venda de produtos naturais e de atendimento de nutricionista.

No que diz respeito ao relacionamento com os formadores as participantes consideram que é bom. Mas com os colegas é um relacionamento pouco profundo. Todas as mulheres consideram que não têm amigos nas turmas que frequentam.

Chamou-nos a atenção o facto de estas mulheres se sentirem satisfeitas com os cursos e sentirem 
que são importantes para as suas vidas, depositando muitas expectativas no estágio profissional após a conclusão dos cursos, nos quais poderão aplicar na prática o que aprenderam.

Compreendemos que as mulheres dos países do leste europeu têm maior dificuldade em acompanhar as aulas do que as outras devido à dificuldade com a língua portuguesa. Mas, embora as dificuldades com a língua leve as duas que frequentam o curso de aeronáutica a dizer que não gostam do curso, não é um facto de desmotivação. O desejo de aprender é mais forte e leva-as a participar mais nas aulas e a exporem todas as suas dúvidas.

Consideramos que este tipo de estudos é importante porque permite-nos compreender como é a inserção dos imigrantes no nosso país. Escutando, por exemplo, como fizemos, as vozes destas mulheres podemos perceber que aspectos devem ser melhorados nos cursos EFA, de modo a atingir níveis superiores de qualificação dos indivíduos pouco escolarizados e a inseri-los de forma eficaz no mercado de trabalho. Reconhece-se que estes cursos podem ser muito importantes na integração dos imigrantes no nosso país. A formação e a qualificação potenciam a integração dos imigrantes bem como constituem uma dimensão essencial da aprendizagem ao longo da vida. Mas algumas questões se levantam. Deverão os cursos EFA integrar formandos que não dominem a língua portuguesa ignorando as diferenças linguísticas e culturais? Sabemos que a educação se consolida quando é promovida a igualdade de oportunidades, mas para que tal aconteça não pode escamotear as diferenças e as constantes mutações a que a sociedade está sujeita. As diferentes culturas presentes num determinado espaço de aprendizagem devem ser valorizadas, devendo ser incluída nas políticas educativas de modo a atender às necessidades educativas dos formandos das comunidades imigrantes, tal como de minorias étnicas ou religiosas.

\section{Notas}

1 Expressão utilizada por Alarcão (2001).

\section{Referências bibliográficas}

ALARCÃO, I. (2001), "Professor-investigador: Que sentido? Que formação?", Cadernos de Formação de Professores, 1, pp. 21-30.

ALVES, M. (2010), "Aprendizagem ao longo da vida: entre a novidade e a reprodução de velhas desigualdades", Revista Portuguesa de Educação, 23 (1), pp. 7-28.

ÁVILA, P. (2008), A literacia dos adultos - Competências-chave na sociedade do conhecimento, Lisboa, Celta Editora.

BATALHA, L. (2008), "Cabo-verdianos em Portugal: comunidade e identidade", in Pedro Góis (org.),
Comunidade(s) cabo-verdiana(s): as múltiplas faces da imigração cabo-verdiana, Lisboa, ACIDI, pp. 25-36.

CABETE, M. (2010), o processo de ensino-aprendizagem do Português enquanto língua de acolhimento, dissertação de Mestrado, Lisboa, Universidade de Lisboa.

CASTRI, F. e F. Cravidão (2011), "Cais de chegada: a imigração no contexto ibérico. Uma perspectiva comparativa", Polígonos. Revista de Geografia, 20, pp. 147-169.

COSTA, P. (2009), "Imigração em Portugal: tendências recentes. Os imigrantes guineenses, ucranianos e brasileiros no mercado de trabalho português", Cadernos do curso de doutoramento em Geografia, 1, pp. 117-140.

COSTA, R. (2011), Formador nos cursos de Educação e Formação de Adultos - Nível Secundário, Trabalho de Projeto, Lisboa, Universidade de Lisboa.

ESTRELA, V. (2013), O Leste em Portugal. A integração de imigrantes ucranianos e a educação de adultos, dissertação de Mestrado, Coimbra, Universidade de Coimbra.

FERREIRA, E.; H. Rato e M. Mortágua (2004), Viagens de Ulisses: efeitos da imigração na economia portuguesa, Lisboa, ACIME.

FERREIRA, P. (2010), A natureza dos motivos para a formação nos adultos que frequentam cursos EFA, dissertação de Mestrado, Coimbra, Universidade de Coimbra.

FONSECA, C. (2010), Porque razão se formam os adultos? Motivações e expectativas dos formandos dos cursos de educação e formação, dissertação de Mestrado, Faro, Universidade do Algarve.

MALHEIROS, J. (2007), "Os brasileiros em Portugal - A síntese do que sabemos", in J. Malheiros (org.), Imigração brasileira em Portugal, Lisboa, ACIDI, pp. 11-37.

MALHEIROS, J.; B. Padilha e F. Rodrigues (2010), Mulheres imigrantes empreendedoras, Lisboa, Comissão para a Cidadania e Igualdade de Género.

MENDES, M. (2008), Mulheres em diáspora: narrativas identitárias de mulheres imigrantes em Portugal, dissertação de Mestrado, Porto, Universidade do Porto.

MIRANDA, J. (2009), Mulheres imigrantes em Portugal: memórias, dificuldades de integração e projectos de vida, Lisboa, ACIDI.

MONTEIRO, A. (2011), "Autonomia e co-responsabilidade ou o lugar da educação de adultos na luta pela inclusão social", Revista Lusófona de Educação, 19, pp. 67-83.

MORTÁGUA, M. J. (2010), "Os estrangeiros em Portugal: cidadãos da União versus nacionais de países terceiros", in Eduardo de Sousa Ferreira, José Paulo Oliveira e Maria João Mortágua (orgs.), Investigação e prática em Economia, Cascais, Princípia.

NEVES, R. (2012), A mulher imigrante brasileira no contexto educacional português: limites e possibilidades, dissertação de Mestrado, Lisboa, Universidade Nova de Lisboa. 
RODRIGUES, D.; T. Correia; I. Pinto; R. Pinto e C. Cruz (2013), "Um Portugal de imigrantes: exercício de reflexão sobre a diversidade cultural e as políticas de integração", Da Investigação às Práticas, 4 (1), pp. 86-109.

ROSA, M.; H. Seabra e T. Santos (2003), Contributo dos "imigrantes" na demografia portuguesa. O papel das populações de nacionalidade estrangeira, Lisboa, ACIME.

SILVA, D. (2013), Voltar à escola 20 anos depois: um desafio pessoal e social, tese de Doutoramento, Lisboa, Universidade Nova de Lisboa.
SOS RACISMO (org.) (2005), Imigração e etnicidade: vivências e trajectórias de mulheres em Portugal, Lisboa, SOS Racismo.

TROVÃO, S. e S. Ramalho (2010), Repertórios femininos em construção num contexto migratório, Lisboa, ACIME.

WALL, K.; C. Nunes e A. Matias (2008), "Trajectórias de mulheres imigrantes em Portugal", VI Congresso Português de Sociologia. Mundos sociais: saberes e práticas, Universidade Nova de Lisboa.

Recebido a 28/06/2016. Aceite para publicação a 22/09/2016.

Luís Filipe da Câmara da Fonseca (luis_filipe_fonseca@hotmail.com). Centro de Emprego e Formação Profissional de Setúbal. Rua António José Baptista, 2910-397 Setúbal, Portugal. 